\title{
Criteria for distinguishing normal from subnormal adrenocortical function using the Synacthen test
}

\author{
W. R. GREIG \\ M.D. (Aberd.), M.R.C.P. (Ed.) \\ Wellcome Clinical Research Fellow \\ J. A. BoYle \\ M.D. (Glasg.), M.R.C.P. (Lond. \& Ed.) \\ Lecturer in Medicine
}

\author{
J. D. MAXWell \\ M.B., B.Sc. (Glasg.), M.R.C.P. (Lond.) \\ McIntyre Research Scholar \\ R. M. LINDSAY \\ M.B. (Glasg.), M.R.C.P. (Ed.) \\ Registrar
}

\author{
Margaret C. K. Browning* \\ B.Sc. (St. And.) \\ Biochemist
}

University Departments of Medicine and Steroid Biochemistry, Royal Infirmary, Glasgow, Scotland

\begin{abstract}
Summary
The Synacthen test consists of the measurement of plasma corticosteroid concentrations by a fluorimetric method before (basal) and $30 \mathrm{~min}$ after a single intramuscular administration of $250 \mu \mathrm{g}$ of tetracosactrin (Synacthen), a synthetic polypeptide with ACTH activity equivalent to that of natural corticotrophin.

In a control group of forty-five subjects the basal plasma corticosteroid level was not lower than $6 \mu \mathrm{g} /$ $100 \mathrm{ml}$ (a lower limit of $5 \mu \mathrm{g} / 100 \mathrm{ml}$ is accepted in the afternoon and evening), the increment was not less than $7 \mu \mathrm{g} / 100 \mathrm{ml}$ and the plasma corticosteroid concentration after Synacthen was not less than 18 $\mu \mathrm{g} / 100 \mathrm{ml}$. From these results the ' $6(5), 7,18$ ' rule was formulated and any patient who failed to satisfy at least two of these criteria was considered to have adrenocortical insufficiency.

The results of the Synacthen test were assessed in forty-six patients who had received long-term steroid therapy, and in fifteen patients with suspected or proven pituitary failure or Addison's disease. Using the ' $6(5), 7,18$ ' rule patients who satisfied two or more of the criteria were considered as having
\end{abstract}

Requests for reprints should be addressed to Dr W. R. Greig, University Department of Medicine, Royal Infirmary, Glasgow. C.4.

* Now at Department of Clinical Chemistry, Maryfield Hospital, Dundee. normal adrenal function, while patients who failed to satisfy these criteria were diagnosed as having adrenal insufficiency. This separation of patients into those with normal and subnormal adrenal function on the basis of the Synacthen test results was found to be reliable as the same division was obtained when the corticotrophin infusion test was performed on groups of the same patients.

The Synacthen test was also carried out in a group of eighty ill patients who did not appear clinically to have endocrine disease and it was considered that the criteria previously determined for distinguishing between a normal and subnormal response to Synacthen were also applicable to this group of patients.

It is suggested that using these criteria the Synacthen test is a simple and reliable screening procedure for the detection or exclusion of adrenocortical failure. A total of 215 tests were carried out on 186 patients without any adverse effects.

\section{Introduction}

Fluorimetric methods of measuring plasma corticosteroids (Braunsberg \& James, 1962; Mattingly, 1962, 1963; Spencer-Peet, Daly \& Smith, 1965; James, Townsend \& Fraser, 1967) have renewed interest in the value of acute adrenal stimulation with corticotrophin as a screening test for adrenocortical hypofunction (Landon et al., 1964; Wood 
et al., 1965; Cope, 1966; Greig et al., 1966; Jasani et al., 1967; Greig et al., 1968). The N-terminal amino acid sequence 1 to 24 of the 1 to 39 chain of natural corticotrophin has been synthesized (Kappeler \& Schwyzer, 1961) and is available under the approved name of tetracosactrin. This polypeptide has an adrenocortical stimulatory action equivalent to that of natural corticotrophin (Landon et al., 1964; Wood et al., 1965; Greig et al., 1966, 1968). The proprietary name of this compound, Synacthen, conveniently describes both its origin and biological activity.

Compared with natural corticotrophin, Synacthen has advantages of chemical purity, assay by weight, high solubility in water and a low antigenic potency. The main antigenic determinants of natural corticotrophin reside in the C-terminal part of the molecule (amino acid sequence 25 to 39 ) which is absent from Synacthen. For this reason patients known to be hypersensitized to the natural hormone may tolerate the synthetic preparation (El-Shaboury, 1965; Fleischer et al. 1965).

When a single intramuscular injection of Synacthen $(250 \mu \mathrm{g}$ in $0.5 \mathrm{ml}$ saline) is given to relatively well subjects, the plasma corticosteroid concentrations increase by two-fold within 30 min (Ohlsen \& Hokfelt, 1965; McGill et al., 1967; Greig et al., 1968), reach a maximum within $30-90 \mathrm{~min}$ and return to the basal level within $4 \mathrm{hr}$ (Wood et al., 1965). This two-fold increase in plasma corticosteroids within $30 \mathrm{~min}$ is consistent and reproducible and forms the basis of a useful screening test of adrenocortical reserve (Wood et al., 1965; Greig et al., 1968).

Although the sex or age of the subject does not appear to influence the response to synthetic corticotrophin, there is inadequate information on the normal biological variation of test results in subjects who do not have disorders of the pituitary-adrenal axis. For this reason quantitative criteria for a response which indicates normal adrenocortical function, and hence the criteria for subnormal adrenocortical function, have not so far been determined. In the present paper we have attempted to provide such criteria by performing the Synacthen test on a control group of relatively well hospital patients, and in a group with adrenocortical insufficiency as revealed by an impaired plasma corticosteroid response to a 4-hr corticotrophin infusion test. The Synacthen test has also been carried out on ill patients with various systemic disorders other than those directly involving the pituitary-adrenal axis. The data from this latter group demonstrate the influence of illness per se on the response to Synacthen, and thus also on the criteria to be adopted for the confirmation or exclusion of adrenocortical insufficiency in these circumstances.

\section{Materials and methods}

Synacthen test (Wood et al., 1965; Greig, 1966)

Synacthen $(250 \mu \mathrm{g})$ was dissolved in $0.5 \mathrm{ml}$ of normal saline and administered as a single intramuscular injection into the deltoid or gluteal muscles. Plasma corticosteroid concentrations were measured before (basal) and $30 \mathrm{~min}$ after the injection.

Corticotrophin infusion test (Christy, Wallace \& Jailer, 1956; Jailer, 1962)

Seventy-five international units of soluble porcine corticotrophin was dissolved in $570 \mathrm{ml}$ of normal saline and given by continuous intravenous infusion over a period of $4 \mathrm{hr}$. Plasma corticosteroid concentrations were measured before (basal) the start of the infusion and at 2, 4 and $6 \mathrm{hr}$ after it was commenced.

In both test procedures plasma corticosteroid concentrations were determined after separation of the red cells from plasma, by the fluorimetric method described by Mattingly (1962). This method gives accurately reproducible measurements over a wide range of plasma corticosteroid concentrations. In our experience the largest standard error of estimation over the range $1-120 \mu \mathrm{g} / 100 \mathrm{ml}$ has been $2 \mu \mathrm{g} /$ $100 \mathrm{ml}$.

\section{Subjects studied \\ Control group}

There were forty-five patients in this group, with a mean age of 47 years (thirty-three females and twelve males). Thirty patients had uncomplicated rheumatoid arthritis, eight osteo-arthropathy, one Reiter's syndrome, one polyarteritis nodosa and five polyarthritis of undetermined aetiology. None had received corticosteroid drugs. None of this group was acutely ill, and biochemical screening tests showed no evidence of hepatic, renal or endocrine disease. The Synacthen test was carried out between 08.00 and 10.00 hours with the subject resting in bed, and in eighteen of the patients the test was repeated on the following morning. In another eighteen subjects the Synacthen test was followed in 2-4 days by the 4-hr corticotrophin infusion test carried out between 07.30 and 11.30 hours with the patient resting in bed. The results of the two tests were then compared.

\section{Corticosteroid treated group}

There were forty-six patients in this group, with a mean age of 57 years (thirty-eight females and eight males). All these patients had rheumatoid arthritis requiring long-term corticosteroid therapy, but none were acutely ill or had clinical or biochemical evidence of hepatic or renal disease. The duration of treatment varied from 3 months to 10 years at the time 
of study, and the drugs employed were prednisone, prednisolone, betamethazone and triamcinolone. These synthetic corticosteroid analogues are not measured by the method employed in this study, and do not interfere with the estimation of endogenous plasma corticosteroids (Mattingly, 1963). Variable suppression of the hypothalamic-pituitaryadrenal axis and thus varying degrees of secondary adrenal atrophy were to be expected in this group (Jasani et al., 1967). The morning dose of corticosteroid drug was postponed until after the Synacthen test had been completed so that at the time of the test a minimum of $12 \mathrm{hr}$ had elapsed since administration of the last dose of corticosteroid. The Synacthen test was carried out between 08.00 and 10.00 hours and in eleven patients this test was repeated on the following morning. In seventeen patients the Synacthen test was followed within 2-4 days by the 4-hr corticotrophin infusion test carried out between 07.30 and 11.30 hours. The results of the two test procedures were then compared.

\section{Group with suspected primary pituitary-adrenal disorder}

There were fifteen patients in this group with a mean age of 38 years (ten females and five males). Of these patients three were subsequently found to have chronic pituitary insufficiency-two with a chromophobe adenoma and one with Sheehan's syndrome. A further three patients were found to have primary adrenal insufficiency-in one due to tuberculosis and in two due to autoimmune adrenalitis (Goudie et al., 1966). In the remaining nine patients full investigations excluded endocrine disease. In these fifteen patients, none of whom was acutely ill, the Synacthen test was carried out once, and was followed in 2 days by the 4-hr corticotrophin infusion test carried out between 08.30 and 12.30 hours.

\section{Group with general medical illnesses}

There were eighty patients in this group with a mean age of 54 years (sixty-one females and nineteen males). These patients were admitted in sequence, either electively or as emergencies, to a busy general medical unit. Patients with a history of corticosteroid therapy, or in whom endocrine disease was present or suspected, were excluded from this group. The Synacthen test was carried out once on each patient either within $2 \mathrm{hr}$ of admission or on the following day. The time of day at which the test was performed varied, and no attempt was made to classify these patients according to their 'admission diagnosis'. The patients, however, were arbitrarily divided according to the duration and severity of their symptoms. On this basis thirty-nine patients had a chronic or subacute illness, and forty-one were acutely ill at the time the Synacthen test was performed. A record was kept of drug therapy, and the presence or absence of haemolysis or jaundice at the time of the test.

\section{Results \\ Control group}

In this group the plasma corticosteroid concentration before Synacthen administration (basal) ranged between $7 \cdot 2$ and $25.8 \mu \mathrm{g} / 100 \mathrm{ml}$ (mean 15.5). After Synacthen the plasma corticosteroid rose significantly in each patient. The minimum rise was $7.7 \mu \mathrm{g} / 100 \mathrm{ml}$ and the maximum rise was $26.1 \mu \mathrm{g} /$ $100 \mathrm{ml}$ (mean 16.4). Thirty minutes after Synacthen the corticosteroid levels ranged from 21.5 to 44.0 $\mu \mathrm{g} / 100 \mathrm{ml}$ (mean 32.5). These three values, basal plasma corticosteroid, increment and the 30-min plasma corticosteroid were, however, interdependent. For this reason the $95 \%$ limits* of the individual values for each of the three sets of data were determined to obtain an index of the normal variation in Synacthen test results when carried out in relatively well patients in the morning. These data are shown in Table 1. From these results

TABLE 1. Criteria for normal and abnormal results from Synacthen test

\begin{tabular}{lccc}
\hline & \multicolumn{3}{l}{ Plasma corticosteroid $(\mu \mathrm{g} / 100 \mathrm{ml})$} \\
\cline { 2 - 4 } & $\begin{array}{l}\text { Before } \\
\text { (basal) }\end{array}$ & Increment & $\begin{array}{c}\text { After } \\
\text { Synacthen } \\
(30 \mathrm{~min})\end{array}$ \\
\hline $\begin{array}{l}\text { Normal range } \\
\text { Above normal }\end{array}$ & $* 6-26$ & $7-25$ & $18-47$ \\
Subnormal & $>26$ & $>25$ & $>47$ \\
\hline
\end{tabular}

* For tests carried out at other times than in the morning the minimum basal corticosteroid is $5 \mu \mathrm{g} / 100 \mathrm{ml}$.

the ' $6,7,18$ ' rule was drawn up in order to classify Synacthen test results as either normal (two or more values attained) or sub-normal (less than two values attained).

\section{Corticosteroid-treated group}

The results of the Synacthen test in this group are shown in detail in Fig. 1. For clarity of presentation the results are separated into two groups. The $95 \%$ limits of the data derived from the control group (Table 1) are shown to indicate the normal response, and the results are categorized according to the ' $6,7,18$ ' rule as described above. Twenty-nine

* Calculated from 2 SD (standard deviations) about the mean since distribution was normal. 

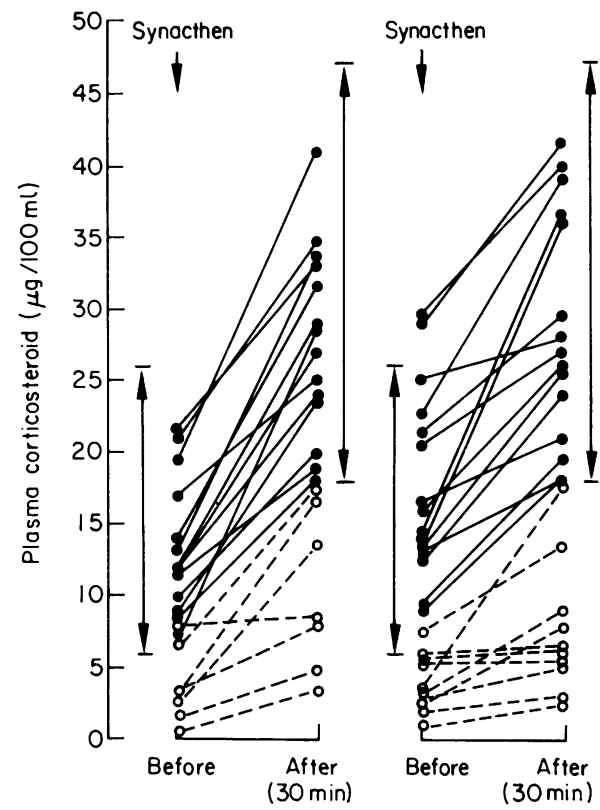

Fig. 1. Results of Synacthen test in forty-six patients treated for rheumatoid arthritis with varying doses of synthetic corticosteroid drugs for periods ranging from 3 months to 10 years. Normal; O, subnormal.

patients showed normal results (twenty-five of these fulfilling all three criteria, while the remaining four satisfied two of the three criteria). Seventeen showed subnormal results, and in these patients a provisional diagnosis of adrenocortical insufficiency was made. In order to evaluate the diagnostic accuracy of the Synacthen test both in respect of normality and of subnormality, the results were compared with those of the 4-hr corticotrophin infusion test. The latter was regarded as a definitive and stringent measurement of adrenocortical reserve (Christy et al., 1956).
This comparison was made in eighteen patients from the control group and in seventeen patients from the corticosteroid group. In the latter, seven were found to satisfy the criteria of the ' $6,7,18$ ' rule and were considered to have normal adrenal function. The remaining ten did not fulfil these criteria and were considered to have adrenal atrophy. Fig. 2 shows the comparison in these three categories of patientcontrol group, corticosteroid-treated group with a normal Synacthen test result, and corticosteroidtreated patients with a subnormal Synacthen response. The comparisons indicate that when the Synacthen test results were normal, those of the corticotrophin infusion test were also normal. Conversely, when the results of the Synacthen test were subnormal by the ' $6,7,18$ ' rule then the corticotrophin infusion test also gave subnormal results. There were no false positive or false negative diagnoses of adrenocortical insufficiency when using the Synacthen test criteria.

\section{Group with suspected primary pituitary-adrenal disorder}

The results of the Synacthen tests in these patients are shown in Fig. 3. In this group the $95 \%$ limits for the normal response are indicated with the basal plasma corticosteroid concentration at $5 \mu \mathrm{g} / 100 \mathrm{ml}$, in contrast to the value of $6 \mu \mathrm{g} / 100 \mathrm{ml}$ shown in Table 1. This difference arises from the diurnal rhythm in plasma corticosteroids, and the level of $5 \mu \mathrm{g} / 100 \mathrm{ml}$ is chosen as a result of our observation during a previous physiological study that this was the lowest normal limit in the evening (McGill et al., 1967). The response to the Synacthen test, however, was unaltered by these diurnal changes and consequently the criteria for a normal Synacthen test at times other than the morning became the ' $5,7,18$ ' rule instead of the ' $6,7,18$ ' rule.
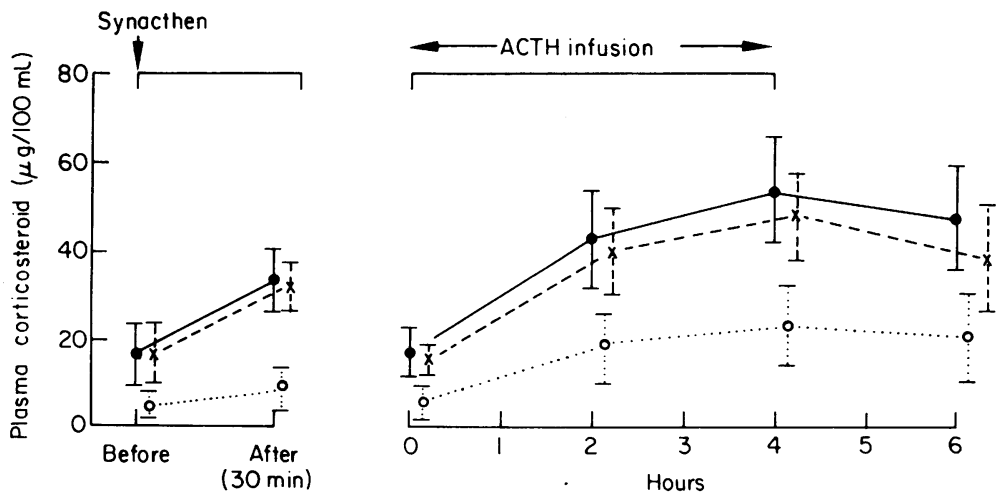

FIG. 2. Comparison of Synacthen test with corticotrophin infusion test in eighteen control subjects $(\Theta)$, and seventeen patients treated with corticosteroid drugs: $\times$, steroid treated (normal), seven; $O$, steroid treated (subnormal), ten. Vertical bars indicate mean \pm standard deviation. 


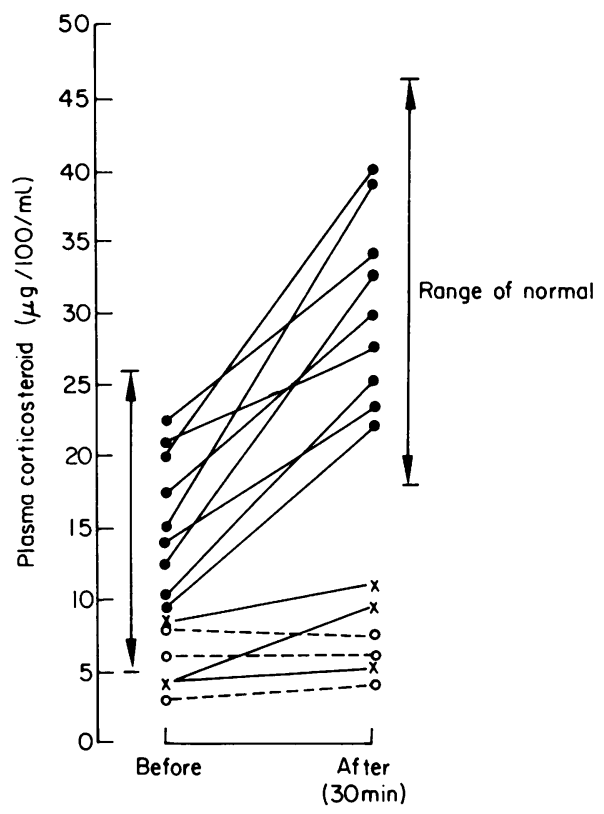

Fig. 3. Results of Synacthen test in fifteen patients with suspected adrenocortical insufficiency (primary or secondary to pituitary failure). $O$, Normal (nine); $\times$, proven hypopituitary (three); $O$, proven primary adrenal atrophy (three).

Fig. 3 shows that in the three patients with longstanding pituitary failure and in the three patients with primary adrenal disease the Synacthen test gave subnormal results. The nine patients who were found by other laboratory investigations to have normal endocrine function also had normal responses to Synacthen. Each patient was also tested with the 4-hr corticotrophin infusion test; a normal response being defined from the results of the corticotrophin infusion test in the control group of patients as shown in Fig. 2. In those patients in whom the Synacthen test was normal the corticotrophin infusion test was also normal, while patients with a subnormal response to Synacthen also responded subnormally to corticotrophin infusion.

\section{Group with general medical illnesses}

The results of the Synacthen test in this group are shown in Fig. 4 and have been divided into those which were within the normal range for resting patients and those which were either above or below this range.

In twenty-eight of the thirty-nine patients with chronic or subacute illnesses the basal plasma corticosteroid level was within the normal range, and in the remaining eleven patients it was above this range. The increment in plasma corticosteroid produced by Synacthen was significant and within the normal range in each patient. In ten of the eleven patients whose basal plasma corticosteroid level was above normal, the post-Synacthen plasma corticosteroid level was also above the normal range. No subnormal test results were found in this group.
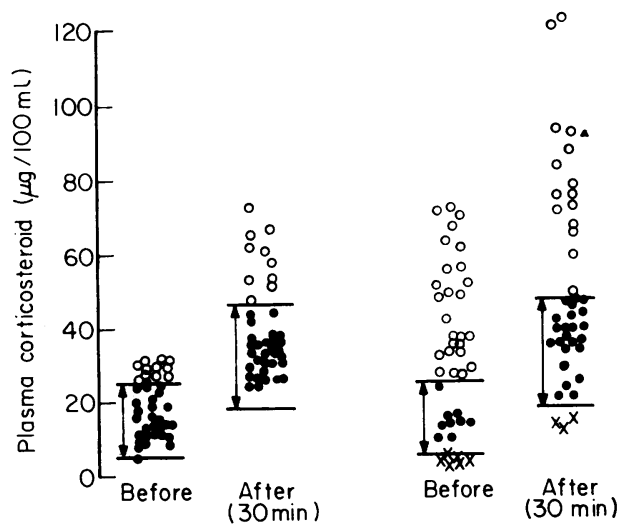

Fig. 4. Results of Synacthen test in eighty patients (thirty-nine with chronic or subacute illness, forty-one acutely ill) with various general medical disorders, excluding primary endocrine disease. $\mathrm{O}$, High; $\mathbf{O}$, normal; $\times$, low.

In contrast, only nine of the forty-one patients with acute illnesses had basal plasma corticosteroids within the normal range. In twenty-six patients the basal value was above the normal range, and in the remaining six patients it was on or below the lower limit of normal. After Synacthen there was a rise in plasma corticosteroid in each patient, but in only twenty-three was the increment within the normal range. In fifteen patients the rise was greater than normal, and in three of the six patients with a low basal plasma corticosteroid level the increment was also low. These three patients were considered on the basis of the ' $5,7,18$ ' criteria to have adrenocortical insufficiency. One of these patients died from irreversible ventricular fibrillation following myocardial infarction. In this patient intravenous hydrocortisone was given without clinical effect. The other two patients died soon after admission from respiratory failure, and were also given hydrocortisone therapy after the Synacthen test was completed.

Permission for post-mortem examination was not obtained.

\section{Duplicate tests}

Analysis* in respect of the significance of differences between the pairs of means of plasma corticosteroid showed satisfactory reproducibility. The maximum differences were as follows-in basal

\footnotetext{
* Student's ' $t$ '-test. Lack of significance $P>0.05$.
} 
corticosteroids it was $5 \mu \mathrm{g} / 100 \mathrm{ml}$; in increments it was $4 \mu \mathrm{g} / 100 \mathrm{ml}$ and after Synacthen it was $8 \mu \mathrm{g} / 100$ $\mathrm{ml}$. It was found that although isolated values differed from day to day, the test results when indicating normal adrenal function on day 1 also indicated this on day 2 . This correlation also held when the results indicated subnormal adrenal function.

A total of 215 Synacthen tests were carried out in 186 subjects without any adverse local or systemic reactions.

\section{Discussion}

The fluorimetric method of measuring plasma corticosteroid concentrations described by Mattingly (1962) measures total plasma 11-hydroxycorticosteroids. Although in man cortisol is the principal free 11-hydroxycorticosteroid in plasma, corticosterone is present in much smaller amounts (rarely exceeding $1 \mu \mathrm{g} / 100 \mathrm{ml}$ ) and is also measured. Administered cortisone and hydrocortisone will be detected by this method, but not corticosteroid analogues such as prednisone, prednisolone, dexamethasone or triamcinolone. Thus the Mattingly method may be used to measure endogenous plasma corticosteroids in patients undergoing treatment with these synthetic corticosteroid preparations. Spurious fluorescence resulting in falsely high measurements occurs in the presence of drugs such as spironolactone, in patients with a raised plasma bilirubin, and where the plasma contains free haemoglobin. If these conditions are excluded, comparisons of the Mattingly method with isotopic procedures (James et al., 1967) indicate that the fluorimetric technique gives values for plasma corticosteroid concentrations which are adequate for clinical purposes.

Basal plasma corticosteroid levels normally show a substantial variation and in our control subjects morning levels ranged from 6 to $26 \mu \mathrm{g} / 100 \mathrm{ml}$. The diurnal rhythm in plasma corticosteroids results in lower basal levels in the afternoon and evening (Mills, 1966). We have found the lower limit of normal for plasma corticosteroids at this time of day to be $5 \mu \mathrm{g} / 100 \mathrm{ml}$ (McGill et al., 1967). These normal biological variations greatly diminish the value of a single estimation of plasma corticosteroid as an index of adrenocortical function. If, however, the basal corticosteroid level, together with the increment and the 30-min value following Synacthen stimulation are assessed in conjunction, diagnostic precision is greatly enhanced.

When the Synacthen test was carried out in control, relatively well patients the lower limits of normal for the basal plasma corticosteroid level, increment, and 30-min post-Synacthen level were $6 \mu \mathrm{g} / 100$ $\mathrm{ml}(5 \mu \mathrm{g} / 100 \mathrm{ml}$ in afternoon and evening), 7 and 18 $\mu \mathrm{g} / 100 \mathrm{ml}$, respectively (Table 1 ). From these results the ' $6(5), 7,18$ ' rule was formulated and a provi- sional diagnosis of adrenocortical insufficiency was made in any patient who could not satisfy any two of these three criteria. These criteria were shown to be valid when they effectively separated patients with normal adrenal function (the majority of whom in fact fulfilled all three criteria), from those with adrenal atrophy as diagnosed by the 4-hr corticotrophin infusion test carried out in the same patients (Fig. 3).

The findings agree in principle with those of previous studies using the Synacthen test, but extend the observations to a quantitative expression of what constitutes normality and, therefore, subnormality. It was, however, important to determine whether these criteria which were based on data from relatively well control patients applied equally to ill patients suffering from disorders other than those involving the endocrine system. It is well recognized that during the stress of illness the normal adrenocortical-hypothalamic-pituitary feedback system may be over-ridden with consequent increased corticotrophin release and enhanced adrenocortical stimulation (Yates \& Urquhart, 1962; Symington, 1964). As a result some ill patients may have increased basal plasma corticosteroid levels, as is demonstrated in Fig. 4. This figure also shows that the increment in corticosteroid level produced by Synacthen was also greater than normal in a large number of the acutely ill patients. However, three patients in this group had both low basal plasma corticosteroid levels and a subnormal response to Synacthen. These three patients died and as necropsy permission was not obtained, it was not possible to examine their adrenals. However, since the characteristic effect of illness is to enhance the basal plasma corticosteroid levels and the response to Synacthen, we consider that abnormal results as gauged by the ' $6(5), 7,18$ ' rule have the same significance in ill patients as in relatively well subjects, and indicate adrenocortical failure until proof to the contrary is obtained.

The Synacthen test, of course, suffers from the limitations of all acute corticotrophin stimulation procedures. A practical disadvantage is its inability to distinguish primary adrenal atrophy from that which is secondary to pituitary disease or the administration of corticosteroid drugs. However, this distinction is not usually an urgent matter, and may in any case be made by other test procedures (Landon et al., 1966; Prunty, 1967). A theoretical disadvantage of this or any other adrenal function test which depends on the measurement of blood levels of steroids following adrenal stimulation by ACTH is that the plasma level of corticosteroids may be influenced not only by the rate of adrenal secretion, but also by the rates of steroid metabolism and loss from plasma. Thus conceivably 'adrenal 
cortical insufficiency' could be diagnosed where adrenal secretion is normal, but corticosteroid metabolism or the rate of egress of cortisol from plasma is enhanced. We have not in practice encountered this difficulty, but investigation of the response to Synacthen in conditions of altered cortisol metabolism would be of interest.

This study presents quantitative criteria for a normal response to Synacthen in adults from data obtained in control hospital patients. It is suggested that if the ' $6(5), 7,18$ ' criteria are adhered to, the Synacthen test is a reliable screening procedure for the confirmation or exclusion of adrenocortical insufficiency. In this connection the Synacthen test may provide a rapid assessment of the possible need for steroid therapy in acutely ill patients, and may also provide a simple guide to the planned withdrawal of corticosteroid drugs after their long-term administration. It must be emphasized, however, that the test is primarily a screening procedure and that a subnormal response (fewer than two of the three criteria satisfied) allows only a provisional diagnosis of adrenocortical insufficiency. Other investigations will be necessary to confirm the diagnosis and make the distinction between primary and secondary adrenal disease. In comparison with corticotrophin infusion, the principal advantages of the Synacthen test are its simplicity, rapidity and safety. Only two venous blood samples and a single intramuscular injection are required, and the test procedure may be repeated within $6 \mathrm{hr}$ if necessary. Since the Synacthen test obviates the necessity for intravenous infusion of fluid it has definite advantages over corticotrophin infusion in patients with incipient or established cardiac failure, and in other conditions where intravenous infusions may be hazardous. The short test is also to be preferred in patients known to be, or likely to be sensitized to natural corticotrophin.

\section{Acknowledgments}

This study was supported by grants from the Wellcome Trust, Ciba Laboratories (U.K.), and from the Arthritis and Rheumatism Council (U.K.).

\section{References}

Braunsberg, H. \& James V.H.T. (1962) The determination of adrenocortical steroids in blood: observations on the reliability of a simple fluorimetric method for cortisol. J. Endocr. 25, 309.

Christy, N.P., Wallace, E.Z. \& Jailer, J.W. (1956) Comparative effects of prednisone and of cortisone in suppressing the response of the adrenal cortex to exogenous adrenocorticotrophin. J. clin. Endocr. 16, 1059.

COPE, C.L. (1966) The adrenal cortex in internal medicine. Brit. med. J. 2, 847, 914 .
El-Shaboury, A.H. (1965) Effect of a synthetic corticotrophic polypeptide on adrenal function in hypertensive asthmatics. Lancet, i, 298.

Fleischer, N., Givens, J.R., Abe, K., Nicholson, W.E. \& LidDlE, G.W. (1965) Studies of A.C.T.H. antibodies and their reactions with inactive analogues of A.C.T.H. J. clin. Invest. 44, 1047.

Goudie, R.B., Anderson, J.R., Gray, K.K. \& Whyte, W.G. (1966) Autoantibodies in Addison's disease. Lancet, i, 1173.

Greig, W.R., Browning, M.C.K., Boyle, J.A. \& MAXWell, J.D. (1966) Effect of the synthetic polypeptide $\boldsymbol{\beta}^{\mathbf{1 - 2 4}}$ (Synacthen) on adrenocortical function. J. Endocr. 34, 411.

Greig, W.R., Jasani, M.K., Boyle, J.A. \& MaXWell, J.D. (1968) Corticotrophin stimulation tests. Mem. Soc. Endocr. $17,175$.

JAILER, J.W. (1962) The Human Adrenal Cortex (Ed. by A. Currie, T. Symington and J.K. Grant), p. 424. Livingstone, Edinburgh.

James, V.H.T., Townsend, J. \& Fraser, R. (1967) Comparison of fluorimetric and isotopic procedures for the determination of plasma cortisol. J. Endocr. 37, 28.

Jasani, M.K., Boyle, J.A., Greig, W.R., Dalakos, T.C., Browning, M.C.K., Thomson, A. \& Buchanan, W.W. (1967) Corticosteroid-induced suppression of the hypothalamo-pituitary-adrenal axis: observations on patients given oral corticosteroids for rheumatoid arthritis. Quart. J. Med. 33, 261.

KAPPELER, H. \& SChWyzer, R. (1961) Die synthese eines Tetracospeptides mit der Aminosauresequenz eines hochaktiven abbaupproduktes des Cortitropins (A.C.T.H.) aus Schweine hypophyse. Helv. Chim. Acta, 44, 1136.

LANDON, J., James, V.H.T., CRYer, R.J., WYNN, V. \& FrankLAND, A.W. (1964) Adrenalcorticotrophin-in man. J. clin. Endocr. 24, 1206.

Landon, J., Greenwood, F.C., Stamp, T.C.V. \& Wynn, V. (1966) The plasma sugar, free fatty acid, cortisol and growth hormone response to insulin and the comparison of this procedure with other tests of pituitary and adrenal function. J. clin. Invest. 45, 437.

McGill, P.E., Greig, W.R., Browning, M.C.K. \& Boyle, J.A. (1967) The plasma cortisol response to Synacthen $\left(\beta^{1-24} \mathrm{Ciba}\right)$ at different times of the day in patients with rheumatic diseases. Ann. Rheum. Dis. 26, 123.

Mattingly, D. (1962) A simple fluorimetric method for the estimation of free 11-hydroxysteroids in human plasma. J. clin. Path. 15, 374.

Mattingly, D. (1963) Plasma steroid levels as a measure of adrenocortical activity. Proc. roy. Soc. Med. 56, 717.

Mills, J.N. (1966) Human circadian rhythms. Physiol Rev. 46, 128.

OHLSEN, P. \& HoKfelt, B. (1965) Effect of synthetic A.C.T.H. on steroid hormone production in man. Acta med. scand. 177, 25.

PRUNTY, F.T.G. (1967) Modern Trends in Endocrinology (Ed. by H. Gardiner-Hill), No. 3, p. 169. Butterworths, London.

Spencer-Peet, J., Daly, J.R. \& Smith, V. (1965) A simple method for improving the specificity of the fluorimetric determinations of adrenal corticosteroids in human plasma. J. Endocr. 31, 235.

Symington, T. (1964) The pathological physiology of the human adrenal cortex and its relationship to hypercorticalism. The Scientific Basis of Medicine Annual Reviews, p. 15. Athlone Press.

WoOd, J.B., Frankland, A.W., James, V.H.T. \& LANDon, J. (1965) A rapid test of adrenocortical function. Lancet, i, 243.

YATES, F.E. \& URQUHART, J. (1962) Control of plasma concentrations of adrenocortical hormones. Physiol. Rev. 42, 359. 